\title{
The role of F-actin in the transport and secretion of chromaffin granules: an historic perspective
}

\author{
Luis M. Gutiérrez ${ }^{1}$ - José Villanueva ${ }^{1}$
}

Received: 14 June 2017 /Revised: 13 July 2017 / Accepted: 14 July 2017 / Published online: 20 July 2017

(C) The Author(s) 2017. This article is an open access publication

\begin{abstract}
Actin is one of the most ubiquitous protein playing fundamental roles in a variety of cellular processes. Since early in the 1980s, it was evident that filamentous actin (Factin) formed a peripheral cortical barrier that prevented vesicles to access secretory sites in chromaffin cells in culture. Later, around 2000, it was described that the F-actin structure accomplishes a dual role serving both vesicle transport and retentive purposes and undergoing dynamic transient changes during cell stimulation. The complex role of the F-actin cytoskeleton in neuroendocrine secretion was further evidenced when it has been proved to participate in the scaffold structure holding together the secretory machinery at active sites and participate in the generation of mechanical forces that drive the opening of the fusion pore, during the first decade of the present century. The complex vision of the multiple roles of Factin in secretion we have acquired to date comes largely from studies performed on traditional 2D cultures of primary cells; however, recent evidences suggest that these may not accurately mimic the $3 \mathrm{D}$ in vivo environment, and thus, more work is now needed on adrenomedullary cells kept in a more "native" configuration to fully understand the role of F-actin in regulating chromaffin granule transport and secretion under physiological conditions.
\end{abstract}

This article is part of the special issue on Chromaffin Cells in Pflügers Archiv - European Journal of Physiology

Luis M. Gutiérrez

luisguti@umh.es

1 Instituto de Neurociencias de Alicante, Consejo Superior de Investigaciones Científicas-Universidad Miguel Hernández, Sant Joan d'Alacant, 03550 Alicante, Spain
Keywords Chromaffin granules $\cdot$ F-actin $\cdot$ Myosin II · Myosin $V \cdot$ Neurosecretory cells $\cdot$ Exocytosis

The filamentous cytoskeletal protein, actin, is the most abundant protein in a multitude of eukaryotic cells, playing a fundamental role in the support of the cell shape and structure, as well as in a variety of cellular processes. Among these processes, it is well stablished that F-actin is a key protein participating not only in the transport of organelles containing active substances but also in the very central events leading to the release of neurotransmitters and hormones by exocytosis $[21$, $31,34,44,59]$.

Initially, it was postulated that F-actin, forming a dense meshwork in the cortical area of neuroendocrine cells, was a retentive system, preventing organelles from accessing the plasma membrane $[3,11,58]$. In the late years, however, it has been shown that the plasticity of the F-actin cytoskeleton allowed for a much more complex function, supporting simultaneously multiple roles as a retentive, as well as transportation system, and structural scaffold for the exocytotic secretory machinery. In the present work, we will review this evolution of our concept of the role of F-actin cytoskeleton in exocytosis in the model of neuroendocrine chromaffin cells.

\section{The pioneer works, the establishment of the "barrier" concept}

At the beginning of the 1980s, with the generalization in the use of immunofluorescence techniques, several works from different laboratories evidenced that the cytoskeletal protein actin, in its filamentous form (F-actin), localized in the peripheral cortex of cultured bovine chromaffin cells forming a continuous ring $[4,29]$. These studies were the base embodying 
the notion of the "barrier" concept for the F-actin cytoskeleton opposing the free access of secretory vesicles to the plasma membrane releasing sites $[3,8,60]$ (See Fig. 1). Years later, the use of the quick-freeze, deep-etch technique in electronic microscopy [36] revealed the details of this dense meshwork of filaments and showed that some areas of the cortex presented discontinuities in this "barrier", as the F-actin fibers where sparse or ran perpendicular to the plasma membrane.

The "barrier" idea was further supported when stimulation of the cells with secretagogues induced the reorganization of a spectrin-like protein, fodrin, forming membrane patches that co-localize with disruption in the cortical F-actin structure [45]. Similarly, cell stimulation with secretagogues induced
80 's

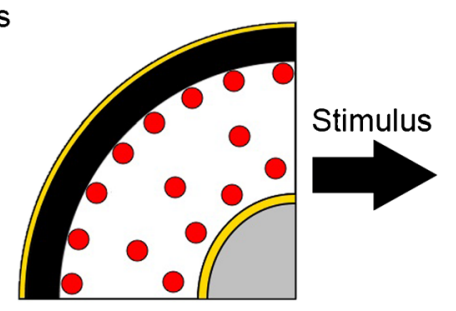

Arround 2000

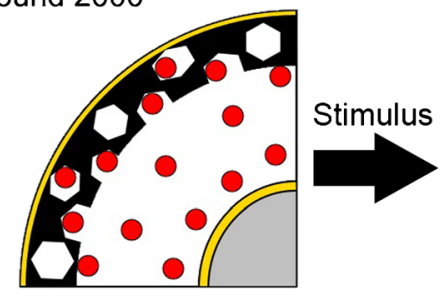

Nowadays

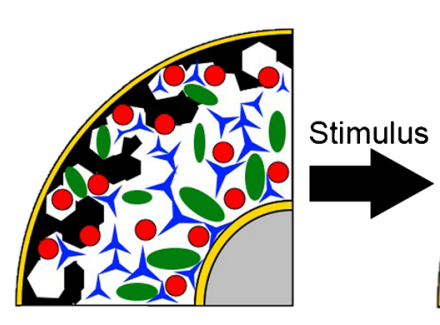
F-Actin cytosqueleton
Chromaffin granules
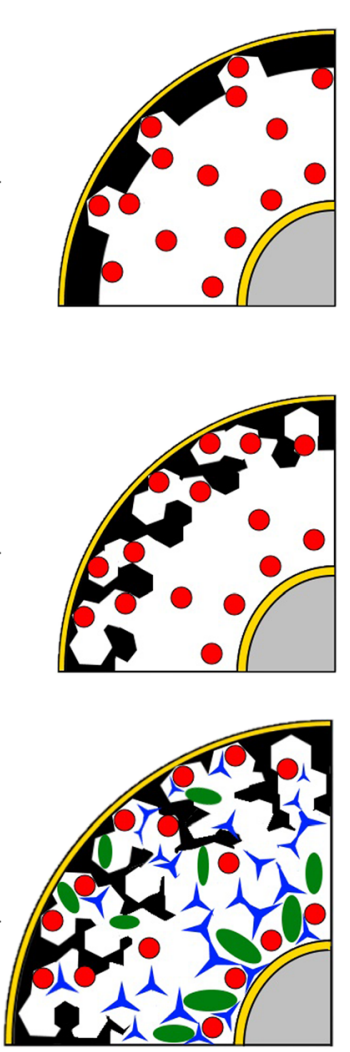

\section{Mitochondria 入 $E R$}

Fig. 1 Historic evolution of the role of F-actin cortex in the secretory process of chromaffin cells. The first works in the 1980s conceived the Factin cortex as a retentive barrier preventing the access of chromaffin granules to the secretory sites. In this context, cell stimulation resulted in the opening of the spaces that allow the access of vesicles to the submembranal zone. Around 2000, the concept evolved to incorporate a dual role as a retentive system and also transport was facilitated during exocytosis by dynamic changes in the F-actin cortical structures. Today, we accept that the cortical F-actin structure is involved in the ubication and transport of other organelles such mitochondria, and that during stimulation, multiple dynamic changes cooperate to produce the coordinated transport of vesicles to active sites (F-actin dynamic cages and the "casting system") the fragmentation of the F-actin cortex [11], a process that was associated with the activity of scinderin, a calciumdependent protein thought to enhance the granules to be release during fast exocytosis [64]. Alternatively, calcium could affect the crosslinking properties of $\mathrm{F}$-actin by protein kinase $\mathrm{C}$ (PKC) phosphorylation of myristoylated alaninerich C kinase substrate (MARKS), causing the partial depolymerisation $[50,57]$.

In some of these early studies, it was evidenced that the role of F-actin was far more complex than a simple retentive system, as for example, the treatment of $\mathrm{PC} 12$ cells with Botulinum toxin $\mathrm{C} 2$, an ADP-ribosylating agent inducing $\mathrm{F}$ actin depolymerisation, has a complex effect favoring secretion at low concentrations and inhibiting the secretory process at higher doses [32]. In addition, discrepancies among different groups stressed the complexity of the F-actin role during exocytosis since there were reports of apparent secretory enhancement and inhibition with the use of substances stabilizing (jasplakinolide or phallotoxins) or disrupting F-actin polymerization (cytochalasins, latrunculins, or clostridial C2 toxin) $[15,17,32]$.

\section{A "dynamic" view, the dual role as a transport and retentive system}

With the development of the total internal reflection fluorescence microscopy (TIRFM) and the end of the 1990s, the "barrier" concept was subjected to an important revision. This technique allowed the visualization of fluorescentlabelled granules located within $300 \mathrm{~nm}$ of the cell limits and therefore immersed in the F-actin meshwork [28, 41]. These studies showed that F-actin trails guided the motion of the vesicles within the F-actin-rich cortical region even though they experienced increased restrictions as they reach the immediate proximity of the plasma membrane [25]. Indeed, dynamic confocal microscopy confirmed later that chromaffin vesicles were transported from the inner regions adjacent to the cell nucleus using both microtubules and Factin fibers and that once the reach the cell cortex, the motion was dependent mostly of the F-actin-myosin system [39, 51].

How can F-actin cortex possibly act as a retentive and also as a transport system? The first vision of the F-actin dynamic changes encompassing secretion was provided by transmitted light scanning combined with fluorescence microscopy using high numerical aperture objectives [19]. In this study, it was revealed that during stimulation, the F-actin structure parallel to the plasma membrane changes transiently to form open spaces and transport tubes allowing access of secretory granules to the secretory sites. These complex reorganizations of F-actin are the basis to understand how the cytoskeletal network can switch from a "retentive" to a "transport" system in a time window of seconds to restore the original disposition 
40-50 s after the initiation of the stimulus and represented a dynamic alternative to the previous ideas based on the simple fragmentation of the F-actin "barrier" (Fig. 1, middle row). In this study, it was observed also the formation of subplasmalemmal spaces devoid of F-actin during prolonged (5 min) stimulation [19], also consistent with previous electron microscopy studies [36].

\section{Dynamic changes required molecular motors}

F-actin changes associated with many cellular processes are driven by molecular motors of the myosin family. Myosin II, undergoing ATP-dependent conformational changes to regulate F-actin dynamics, was proved to be present in the cortical area of chromaffin cells in 1984 [60] and to be regulated by calcium-dependent phosphorylation during the secretory cycle $[9,22,23]$. The importance of the activity of such a motor of myosin II was later demonstrated when the inhibition of the myosin light chain kinase partially affected secretion $[26,46]$.

In addition to myosin II, myosin V was also abundant in the cytosol of chromaffin cells $[38,48]$ and was found to associate with chromaffin granules [49]. Importantly, it was proven that myosin $\mathrm{V}$ regulates the association of the vesicles with the cortical cytoskeleton in PC12 cells [51]. Myosin Va seems to be essential for the motion of the vesicles in the subplasmalemmal area, an activity that is mediated by the small GTPase Rab 27 and the MyRIP protein [12].

More recently, it was shown that myosin VI was able to recruit vesicles to the cortical zone in a calcium-dependent process; this depends on the small insert isoform located in the cargo domain of myosin VI [55]. This mean that conventional myosins V and VI could be playing similar roles operating in concert to ensure the supply of vesicles during the exhaustion of vesicular pools driven by prolonged stimulation.

Taken together, an actual and integrated view of chromaffin granule transport associated with F-actin depicts two different mechanisms acting in concert, a processive motion of vesicles along F-actin trails using conventional myosins V and VI and a non-processive transport of the granules entrapped in F-actin cages and controlled by the activity of myosin II.

\section{Not only transport! Actomyosin role in the fusion event}

The study of the fusion kinetics with amperometry at the single vesicle fusion level [67] has been instrumental in showing that myosin motors influence not only vesicle transport but the very final events of membrane fusion. In 2004, Neco and colleagues expressed a non-phosphorylatable form of myosin II in chromaffin cells and found that F-actin and myosin II influence the kinetics of catecholamine release through the fusion pore [40], specifically prolonging the open time as was described later by using the patch amperometry technique [37]. Similarly, the pharmacological inhibition of F-actin polymerization and myosin II activity slowed release kinetics without affecting quantal size [6].

Recent works suggest that F-actin-myosin II may exert a tensional force facilitating neurotransmitter release by acting either at the plasma membrane-vesicle interface [16] or at the level of a granule coat [35]. In chromaffin cell, it is likely that actomyosin forces influence the plasma membrane tension to drive relaxation after F-actin stabilization [62], decrease membrane tension after myosin inhibition [7], and synchronize vesicle transport during stimulation [42]. In any case, the exquisite control of the cytoskeletal actomyosin appears to regulate even the mode of fusion promoting the "kiss-and-run" partial release at low-frequency stimulations and enhancing the full collapse of the granules at higher frequencies by destabilizing the F-actin structures [13]. Similarly, experiments conducted in PC 12 cells and the expression of vesicular "cargo" proteins with variable size and, therefore, diffusion rates through the fusion pore confirmed these results [1].

\section{The interphase between the plasma membrane and the cytoskeleton}

There is no doubt that the F-actin cortical structure is a central piece of the organization of the secretory machinery, but there are also many evidences that the polymerization of F-actin "de novo" is also playing an important role.

In chromaffin cells, a molecular cascade involving small GTPases, such as Cdc42, trigers the formation of actin filaments in the submembranal area [15], and this increases the secretory activity. This F-actin recruitment seems to be mediated throught N-WASP and the Arp2/3 complex, two factors governing actin nucleation during propulsion of secretory vesicles [54]. These initial studies have been supported by a recent work probing that glycerophospholipid phosphatidylinositol 4,5-bisphosphate (PtdIns(4,5)P2) coordinates the translocation of secretory vesicles to their docking sites on the plasma membrane in a Cdc42-dependent manner $[65,66]$. PtdIns(4,5)P2 forms clusters that, in addition to nucleating the formation of F-actin, also interact with SNARE proteins [2] and act as a "beacon" for vesicle guidance to active sites. The ability of F-actin to influence the modality and localization of the molecular machinery of exocytosis has recently been evidenced by the demonstration that PC12 cells emit filopodial extensions in response to secretagogue stimulation, an effect that is driven by F-actin trails that are capable of guiding secretory vesicles to newly uncovered secretory sites [43]. 


\section{F-actin involvement in the arrangement of secretory sites}

Before the 1980s, it was well established that in neurons, exocytosis takes place in specialized spatial areas of the synaptic terminals called "active zones" [10, 27]. Later on, in a seminal paper, Sankaranayanan et al. showed that cortical Factin plays a scaffold function avoiding diffusion of the molecular players of neurosecretion [52]. Therefore, a key question was if there are similar structures in neuroendocrine models, such chromaffin cells, and if F-actin plays a similar cohesive role.

Again, amperometry was seminal to show that in chromaffin cell local and restricted elevations of calcium, the so called "hot spots," where coincident with secretory events [47]. This was the first evidence of the localized nature of the secretory response in chromaffin cells, and it was confirmed later when for most granules, calcium signals are originated within $300 \mathrm{~nm}$ of its location in the submembranal space [5]. Finally, using inmunolocalization techniques, it was shown that a $1 / 3$ of SNARE microdomains co-localized with calcium channel spots and that these zones are the preferential sites for exocytosis [30]. This co-localization occurring between voltage-dependent calcium channels and secretory vesicles were first studied in early "patch clamp" studies and described in classical synapses [53].

The F-actin cytoskeleton appears to be the cohesive factor to hold these "pseudo" active sites since the expression of exogenous SNAP-25 appears to co-localize with calcium channels in the borders of F-actin cortical cytoskeletal cages [61], and this was later confirmed with the "native" proteins using immunocytochemistry [56]. Interestingly, in this study [56], it was proposed, by using mathematical models, that the organization of the secretory machinery in association with the borders of F-actin cortical structures forming cages or cavities in the subplasmalemmal space results in robust calcium confined elevations that accelerate the secretory kinetics when compared with random distributions of this machinery.

The organization of the secretory machinery has been studied in a variety of systems ranging from exocrine to neuroendocrine, and neuronal cells using atomic force and electron microscopy, leading to the description of the "porosome" as permanent cup-shaped structures associating SNARE proteins, NSF ATPase, and calcium channel subunits [24]. Among these constituents, it was described that actin was present together with other cytoskeletal proteins such as vimentin and $\alpha$-fodrin.

Taking together, the emerging view suggests that the cortical F-actin cytoskeleton is an "integrative" factor associating the molecular components of the secretory machinery to configure a cytoarchitecture favoring the fine tuning of the secretory responses.

\section{Latest discoveries and shadows}

In the later years, it has been re-inforce the role of F-actin governing the transport of the organelles, extending this control not only to chromaffin granules but also to other organelles such as mitochondria [63], playing a fundamental role in the generation of subpopulations of cortical and perinuclear organelles. In addition, "new" visions of this transport have been described to include the existence of conveyor belts to drive the displacement of entire cortical cytoplasmic regions toward the plasma membrane during cell stimulation [33]. In the proximity of the membrane, Factin and myosin II appear to also coordinate the "casting net" system to replenish in the "docking" areas the chromaffin granules that has been released [42] (Fig. 1, lower row). Similarly, the role of F-actin during the fusion process has been sustained recently by articles enclosing new details of the molecular players. For example, the F-actin-binding protein cortactin has been implicated in the regulation of the duration of the fusion pore [20] and annexin A2 promoting F-actin-mediated bundling of the membrane is essential for the docking of the incoming granules [14].

In consequence, during the last 30 years, our vision of the role of the F-actin cytoskeleton in the secretory process in the neuroendocrine model of chromaffin cells has evolved from a simple vision of a retentive system preventing the granules to fuse in the absence of stimulation to a very complex function involving transitory dynamic changes that facilitate multiple roles as a scaffold structure supporting organelle and secretory machinery localization, coordinated organelle transport, and mechanical forces necessary for the correct opening of the fusion pore. In the context of this progress, it is important to notice, however, that most of our knowledge is based in the use of isolated and cultured cells, and recently, it has been demonstrated that the F-actin cytoskeleton of cultured chromaffin cells differs from that present in "native" cells forming part of the adrenal medulla [18]. The F-actin cytoskeleton is a complex network that extends through the whole cytosol in "native" cells, and it is destabilized in isolated cultured cells forming the "characteristic" peripheral cortical structure, and this, in consequence, changes the distribution of organelles and proteins that influence the secretory kinetics. Therefore, to fully understand the role of the F-actin cytoskeleton in "physiological" conditions, it will be necessary to develop techniques involving the use of "native cells" in a 3D in vivo like environment as found in adrenomedullary tissue.

Acknowledgements This work was supported by a grant from the Spanish Ministry of Economy and Competitiveness (MEC, Fondos FEDER: BFU2015-63684-P) to LMG. 
Open Access This article is distributed under the terms of the Creative Commons Attribution 4.0 International License (http:// creativecommons.org/licenses/by/4.0/), which permits unrestricted use, distribution, and reproduction in any medium, provided you give appropriate credit to the original author(s) and the source, provide a link to the Creative Commons license, and indicate if changes were made.

\section{References}

1. Aoki R, Kitaguchi T, Oya M, Yanagihara Y, Sato M, Miyawaki A, Tsuboi T (2010) Duration of fusion pore opening and the amount of hormone released are regulated by myosin II during kiss-and-run exocytosis. Biochem J 429:497-504

2. Aoyagi K, Sugaya T, Umeda M, Yamamoto S, Terakawa S, Takahashi M (2005) The activation of exocytotic sites by the formation of phosphatidylinositol 4,5-bisphosphate microdomains at syntaxin clusters. J Biol Chem 280:17346-17352

3. Aunis D, Bader MF (1988) The cytoskeleton as a barrier to exocytosis in secretory cells. J Exp Biol 139:253-266

4. Aunis D, Guerold B, Bader MF, Cieselski-Treska J (1980) Immunocytochemical and biochemical demonstration of contractile proteins in chromaffin cells in culture. Neuroscience 5:22612277

5. Becherer U, Moser T, Stuhmer W, Oheim M (2003) Calcium regulates exocytosis at the level of single vesicles. Nat Neurosci 6: 846-853

6. Berberian K, Torres AJ, Fang Q, Kisler K, Lindau M (2009) F-actin and myosin II accelerate catecholamine release from chromaffin granules. J Neurosci 29:863-870

7. Bretou M, Jouannot O, Fanget I, Pierobon P, Larochette N, Gestraud P, Guillon M, Emiliani V, Gasman S, Desnos C, Lennon-Dumenil AM, Darchen F (2014) Cdc42 controls the dilation of the exocytotic fusion pore by regulating membrane tension. Mol Biol Cell 25:3195-3209

8. Burgoyne RD, Cheek TR (1987) Reorganisation of peripheral actin filaments as a prelude to exocytosis. Biosci Rep 7:281-288

9. Cote A, Doucet JP, Trifaro JM (1986) Phosphorylation and dephosphorylation of chromaffin cell proteins in response to stimulation. Neuroscience 19:629-645

10. Couteaux R, Pecot-Dechavassine M (1970) Synaptic vesicles and pouches at the level of "active zones" of the neuromuscular junction. C R Acad Sci Hebd Seances Acad Sci D 271:2346-2349

11. Cheek TR, Burgoyne RD (1986) Nicotine-evoked disassembly of cortical actin filaments in adrenal chromaffin cells. FEBS Lett 207: $110-114$

12. Desnos C, Schonn JS, Huet S, Tran VS, El-Amraoui A, Raposo G, Fanget I, Chapuis C, Menasche G, de Saint BG, Petit C, Cribier S, Henry JP, Darchen F (2003) Rab27A and its effector MyRIP link secretory granules to F-actin and control their motion towards release sites. J Cell Biol 163:559-570

13. Doreian BW, Fulop TG, Smith CB (2008) Myosin II activation and actin reorganization regulate the mode of quantal exocytosis in mouse adrenal chromaffin cells. J Neurosci 28:4470-4478

14. Gabel M, Delavoie F, Demais V, Royer C, Bailly Y, Vitale N, Bader MF, Chasserot-Golaz S (2015) Annexin A2-dependent actin bundling promotes secretory granule docking to the plasma membrane and exocytosis. J Cell Biol 210:785-800

15. Gasman S, Chasserot-Golaz S, Malacombe M, Way M, Bader MF (2004) Regulated exocytosis in neuroendocrine cells: a role for subplasmalemmal Cdc42/N-WASP-induced actin filaments. Mol Biol Cell 15:520-531
16. Gauthier NC, Masters TA, Sheetz MP (2012) Mechanical feedback between membrane tension and dynamics. Trends Cell Biol 22: 527-535

17. Gil A, Rueda J, Viniegra S, Gutierrez LM (2000) The F-actin cytoskeleton modulates slow secretory components rather than readily releasable vesicle pools in bovine chromaffin cells. Neuroscience 98:605-614

18. Gimenez-Molina Y, Villanueva J, Nanclares C, Lopez-Font I, Viniegra S, Frances MDM, Gandia L, Gil A, Gutierrez LM (2017) The differential organization of F-actin alters the distribution of organelles in cultured when compared to native chromaffin cells. Front Cell Neurosci 11:135

19. Giner D, Neco P, Frances MM, Lopez I, Viniegra S, Gutierrez LM (2005) Real-time dynamics of the F-actin cytoskeleton during secretion from chromaffin cells. J Cell Sci 118:2871-2880

20. Gonzalez-Jamett AM, Guerra MJ, Olivares MJ, Haro-Acuna V, Baez-Matus X, Vasquez-Navarrete J, Momboisse F, MartinezQuiles N, Cardenas AM (2017) The F-actin binding protein Cortactin regulates the dynamics of the exocytotic fusion pore through its SH3 domain. Front Cell Neurosci 11:130

21. Gutierrez LM (2012) New insights into the role of the cortical cytoskeleton in exocytosis from neuroendocrine cells. Int Rev Cell Mol Biol 295:109-137

22. Gutierrez LM, Ballesta JJ, Hidalgo MJ, Gandia L, Garcia AG, Reig JA (1988) A two-dimensional electrophoresis study of phosphorylation and dephosphorylation of chromaffin cell proteins in response to a secretory stimulus. J Neurochem 51:1023-1030

23. Gutierrez LM, Hidalgo MJ, Palmero M, Ballesta JJ, Reig JA, Garcia AG, Viniegra S (1989) Phosphorylation of myosin light chain from adrenomedullary chromaffin cells in culture. Biochem J 264:589-596

24. Jena BP, Cho SJ, Jeremic A, Stromer MH, and bu-Hamdah R. Structure and composition of the fusion pore. Biophys $\mathrm{J} 84$ : 1337-1343, 2003

25. Johns LM, Levitan ES, Shelden EA, Holz RW, Axelrod D (2001) Restriction of secretory granule motion near the plasma membrane of chromaffin cells. J Cell Biol 153:177-190

26. Kumakura K, Sasaki K, Sakurai T, Ohara-Imaizumi M, Misonou H, Nakamura S, Matsuda Y, Nonomura Y (1994) Essential role of myosin light chain kinase in the mechanism for MgATPdependent priming of exocytosis in adrenal chromaffin cells. J Neurosci 14:7695-7703

27. Landis DM, Hall AK, Weinstein LA, Reese TS (1988) The organization of cytoplasm at the presynaptic active zone of a central nervous system synapse. Neuron 1:201-209

28. Lang T, Wacker I, Wunderlich I, Rohrbach A, Giese G, Soldati T, Almers W (2000) Role of actin cortex in the subplasmalemmal transport of secretory granules in PC-12 cells. Biophys J 78: 2863-2877

29. Lee RW, Trifaro JM (1981) Characterization of anti-actin antibodies and their use in immunocytochemical studies on the localization of actin in adrenal chromaffin cells in culture. Neuroscience 6:20872108

30. Lopez I, Giner D, Ruiz-Nuno A, Fuentealba J, Viniegra S, Garcia AG, Davletov B, Gutierrez LM (2007) Tight coupling of the tSNARE and calcium channel microdomains in adrenomedullary slices and not in cultured chromaffin cells. Cell Calcium 41:547558

31. Malacombe M, Bader MF, Gasman S (2006) Exocytosis in neuroendocrine cells: new tasks for actin. Biochim Biophys Acta 1763: $1175-1183$

32. Matter K, Dreyer F, Aktories K (1989) Actin involvement in exocytosis from PC12 cells: studies on the influence of botulinum $\mathrm{C} 2$ toxin on stimulated noradrenaline release. J Neurochem 52:370 376 
33. Maucort G, Kasula R, Papadopulos A, Nieminen TA, RubinszteinDunlop H, and Meunier FA. Mapping organelle motion reveals a vesicular conveyor belt spatially replenishing secretory vesicles in stimulated chromaffin cells. Plos One 9: 2014

34. Meunier FA, Gutierrez LM (2016) Captivating new roles of F-actin cortex in exocytosis and bulk endocytosis in neurosecretory cells. Trends Neurosci 39:605-613

35. Miklave P, Ehinger K, Sultan A, Felder T, Paul P, Gottschalk KE, Frick M (2015) Actin depolymerisation and crosslinking join forces with myosin II to contract actin coats on fused secretory vesicles. J Cell Sci 128:1193-1203

36. Nakata T, Hirokawa N (1992) Organization of cortical cytoskeleton of cultured chromaffin cells and involvement in secretion as revealed by quick-freeze, deep-etching, and double-label immunoelectron microscopy. J Neurosci 12:2186-2197

37. Neco P, Fernandez-Peruchena C, Navas S, Gutierrez LM, de Toledo GA, Ales E (2008) Myosin II contributes to fusion pore expansion during exocytosis. J Biol Chem 283:10949-10957

38. Neco P, Gil A, del Mar FM, Viniegra S, Gutierrez LM (2002) The role of myosin in vesicle transport during bovine chromaffin cell secretion. Biochem J 368:405-413

39. Neco P, Giner D, del Mar FM, Viniegra S, Gutierrez LM (2003) Differential participation of actin- and tubulin-based vesicle transport systems during secretion in bovine chromaffin cells. Eur J Neurosci 18:733-742

40. Neco P, Giner D, Viniegra S, Borges R, Villarroel A, Gutierrez LM (2004) New roles of myosin II during vesicle transport and fusion in chromaffin cells. J Biol Chem 279:27450-27457

41. Oheim M, Stuhmer W (2000) Tracking chromaffin granules on their way through the actin cortex. Eur Biophys J 29:67-89

42. Papadopulos A, Gomez GA, Martin S, Jackson J, Gormal RS, Keating DJ, Yap AS, and Meunier FA. Activity-driven relaxation of the cortical actomyosin II network synchronizes Munc18-1-dependent neurosecretory vesicle docking. Nature Communications 6: 2015

43. Papadopulos A, Martin S, Tomatis VM, Gormal RS, Meunier FA (2013) Secretagogue stimulation of neurosecretory cells elicits filopodial extensions uncovering new functional release sites. J Neurosci 33:19143-19153

44. Papadopulos A, Tomatis VM, Kasula R, Meunier FA (2013) The cortical acto-myosin network: from diffusion barrier to functional gateway in the transport of neurosecretory vesicles to the plasma membrane. Front Endocrinol (Lausanne) 4:153

45. Perrin D, Aunis D (1985) Reorganization of alpha-fodrin induced by stimulation in secretory cells. Nature 315:589-592

46. Reig JA, Viniegra S, Ballesta JJ, Palmero M, Guitierrez LM (1993) Naphthalenesulfonamide derivatives ML9 and W7 inhibit catecholamine secretion in intact and permeabilized chromaffin cells. Neurochem Res 18:317-323

47. Robinson IM, Finnegan JM, Monck JR, Wightman RM, Fernandez JM (1995) Colocalization of calcium entry and exocytotic release sites in adrenal chromaffin cells. Proc Natl Acad Sci U S A 92: 2474-2478

48. Rose SD, Lejen T, Casaletti L, Larson RE, Pene TD, Trifaro JM (2002) Molecular motors involved in chromaffin cell secretion. Ann N Y Acad Sci 971:222-231

49. Rose SD, Lejen T, Casaletti L, Larson RE, Pene TD, Trifaro JM (2003) Myosins II and V in chromaffin cells: myosin V is a chromaffin vesicle molecular motor involved in secretion. J Neurochem 85:287-298

50. Rose SD, Lejen T, Zhang L, Trifaro JM (2001) Chromaffin cell Factin disassembly and potentiation of catecholamine release in response to protein kinase $\mathrm{C}$ activation by phorbol esters is mediated through myristoylated alanine-rich $\mathrm{C}$ kinase substrate phosphorylation. J Biol Chem 276:36757-36763
51. Rudolf R, Kogel T, Kuznetsov SA, Salm T, Schlicker O, Hellwig A, Hammer JA III, Gerdes HH (2003) Myosin Va facilitates the distribution of secretory granules in the F-actin rich cortex of PC12 cells. J Cell Sci 116:1339-1348

52. Sankaranarayanan S, Atluri PP, Ryan TA (2003) Actin has a molecular scaffolding, not propulsive, role in presynaptic function. Nat Neurosci 6:127-135

53. Seward EP, Nowycky MC (1996) Kinetics of stimulus-coupled secretion in dialyzed bovine chromaffin cells in response to trains of depolarizing pulses. J Neurosci 16:553-562

54. Taunton J, Rowning BA, Coughlin ML, Wu M, Moon RT, Mitchison TJ, and Larabell CA. Actin-dependent propulsion of endosomes and lysosomes by recruitment of N-WASP. J Cell Biol 148: 519-530, 2000

55. Tomatis VM, Papadopulos A, Malintan NT, Martin S, Wallis T, Gormal RS, Kendrick-Jones J, Buss F, Meunier FA (2013) Myosin VI small insert isoform maintains exocytosis by tethering secretory granules to the cortical actin. J Cell Biol 200:301-320

56. Torregrosa-Hetland CJ, Villanueva J, Lopez-Font I, GarciaMartinez V, Gil A, Gonzalez-Velez V, Segura J, Viniegra S, Gutierrez LM (2010) Association of SNAREs and calcium channels with the borders of cytoskeletal cages organizes the secretory machinery in chromaffin cells. Cell Mol Neurobiol 30:1315-1319

57. Trifaro J, Rose SD, Lejen T, Elzagallaai A (2000) Two pathways control chromaffin cell cortical F-actin dynamics during exocytosis. Biochimie 82:339-352

58. Trifaro JM, Bader MF, Doucet JP (1985) Chromaffin cell cytoskeleton: its possible role in secretion. Can J Biochem Cell Biol 63: 661-679

59. Trifaro JM, Gasman S, Gutierrez LM (2008) Cytoskeletal control of vesicle transport and exocytosis in chromaffin cells. Acta Physiol (Oxf) 192:165-172

60. Trifaro JM, Kenigsberg RL, Cote A, Lee RW, Hikita T (1984) Adrenal paraneurone contractile proteins and stimulus-secretion coupling. Can J Physiol Pharmacol 62:493-501

61. Villanueva J, Torregrosa-Hetland CJ, Gil A, Gonzalez-Velez V, Segura J, Viniegra S, Gutierrez LM (2010) The organization of the secretory machinery in chromaffin cells as a major factor in modeling exocytosis. HFSP J 4:85-92

62. Villanueva J, Torres V, Torregrosa-Hetland CJ, Garcia-Martinez V, Lopez-Font I, Viniegra S, and Gutierrez LM. F-actin-myosin II inhibitors affect chromaffin granule plasma membrane distance and fusion kinetics by retraction of the cytoskeletal cortex. J Mol Neurosci 2012

63. Villanueva J, Viniegra S, Gimenez-Molina Y, Garcia-Martinez V, Exposito-Romero G, Frances MD, Garcia-Sancho J, Gutierrez LM (2014) The position of mitochondria and ER in relation to that of the secretory sites in chromaffin cells. J Cell Sci 127:5105-5114

64. Vitale ML, Seward EP, Trifaro JM (1995) Chromaffin cell cortical actin network dynamics control the size of the release-ready vesicle pool and the initial rate of exocytosis. Neuron 14:353-363

65. Wen PJ, Osborne SL, Meunier FA (2012) Phosphoinositides in neuroexocytosis and neuronal diseases. Phosphoinositides and Disease 362:87-98

66. Wen PJ, Osborne SL, Zanin M, Low PC, Wang HT, Schoenwaelder SM, Jackson SP, Wedlich-Soldner R, Vanhaesebroeck B, Keating DJ, Meunier FA (2011) Phosphatidylinositol(4,5)bisphosphate coordinates actin-mediated mobilization and translocation of secretory vesicles to the plasma membrane of chromaffin cells. Nat Commun 2:491

67. Wightman RM, Jankowski JA, Kennedy RT, Kawagoe KT, Schroeder TJ, Leszczyszyn DJ, Near JA, Diliberto EJ Jr, Viveros OH (1991) Temporally resolved catecholamine spikes correspond to single vesicle release from individual chromaffin cells. Proc Natl Acad Sci U S A 88:10754-10758 